\title{
FROM ABOVE THE FOREST INTO THE SOIL - HOW WIND AFFECTS SOIL GAS TRANSPORT THROUGH AIR PRESSURE FLUCTUATIONS
}

Thomas Laemmel ${ }^{a}$, Manuel Mohr ${ }^{b}$, Bernard Longdoz ${ }^{c}$, Helmer Schack-Kirchner ${ }^{a}$, Friederike Lang ${ }^{a}$, Dirk Schindler ${ }^{\mathrm{b}}$, Martin Maier ${ }^{\mathrm{a}, \mathrm{d}}$

${ }^{a}$ Soil Ecology, University of Freiburg, Bertoldstrasse 17, 79098, Freiburg, Germany

${ }^{\mathrm{b}}$ Environmental Meteorology, University of Freiburg Werthmannstrasse 10, 79085, Freiburg Germany

'TERRA Teaching and Research Centre, Gembloux Agro-Bio-Tech, University of Liège, 8, avenue de la Faculté, 5030, Gembloux, Belgium

${ }^{d}$ Forest Research Institute Baden Wuerttemberg (FVA), Wohnhaldestrasse 4, 79100, Freiburg Germany

KEYWORDS: Pressure-pumping Soil gas transport Air pressure fluctuations Tracer gas

ABBREVIATIONS: PPE, pressure-pumping effect

\begin{abstract}
Molecular diffusion is commonly assumed as main physical process of gas transport in soils. However, non-diffusive gas transport processes like the so-called pressure-pumping effect can affect soil gas transport significantly. The pressure-pumping effect has only been detected indirectly and the underlying mechanisms remain unclear. Using a novel in situ method the soil gas transport at a conifer forest site was monitored over a seven-week period. Airflow and air pressure were simultaneously measured above and below the forest canopy and air pressure was also measured in the soil. During episodes of high above-canopy wind speed, the effective soil gas diffusivity temporarily increased due to pressure-pumping. The enhancement of the gas transport rate in the topsoil reached up to $30 \%$. We found that the best meteorological proxy explaining this effect was related to air pressure fluctuations measured at soil surface and not the mean wind speed directly above ground. While sub-canopy wind speeds continuously decreased from the bottom of the tree crown to the soil surface, amplitudes of the air pressure fluctuations were nearly constant in the whole sub-canopy profile and in the soil. We hypothesize that the air pressure fluctuations responsible for pressure-pumping are related to characteristics of above-canopy airflow rather than to airflow directly above the soil surface.
\end{abstract}




\section{Introduction}

Gas exchange at the soil-atmosphere interface is of particular interest in the current discussion on climate change. Soil gas emissions are driven by gas production and consumption in the soil, mediated by the porous soil structure, and physical gas transport processes. Gas production and consumption in the soil are mainly related to biological processes in the soil (Smith et al., 2003). The porous soil structure is steadily changing, e.g., due to water gain, loss, and redistribution, natural evolution of the matrix structure due to earthworms, or deformation of the matrix structure due to compaction (Nawaz et al., 2013). Molecular diffusion is considered as the main physical gas transport process in the soil (Buckingham, 1904; Scanlon et al., 2001).

Studies have shown that non-diffusive gas transport processes can substantially enhance diffusion-limited soil gas transport. Advection of air can be generated in highly porous surface layers, like moss or mulch, by wind blowing over rough surfaces (Hirsch et al., 2004; Novak et al., 2000a) in areas with sparse vegetation where high wind speeds directly above the ground can develop. Advection can also be generated by the pressure-pumping effect (PPE) caused by "shortperiod atmospheric turbulence, longer-period barometric changes, and quasi-static pressure fields induced by wind blowing across irregular topography" (Massman et al., 1997). Barometric pressure-pumping is typically caused by air pressure changes of several tens of hectopascal (hPa) in one to two days (Auer et al., 1996; Clements and Wilkening, 1974; Massmann and Farrier, 1992). Pressure-pumping due to pressure fields induced by wind blowing across irregular topography was demonstrated over a waste pile (Amos et al., 2009) and over snow features like dunes and ripples (Colbeck, 1989). Pressure-pumping due to" short-period atmospheric turbulence "refers to air pressure fluctuations with frequencies lower than $0.1 \mathrm{~Hz}$ which induce an enhancement of the diffusion-limited soil gas transport (Massman et al., 1997; Mohr et al., 2016).

Laboratory experiments showed that wind as well as air pressure fluctuations can substantially enhance gas transport through porous media such as soil (Maier et al., 2012; Poulsen et al., 2017a, 2017b; Pourbakhtiar et al., 2017). In experiments investigating the effect of wind relatively high wind speeds ( $>1 \mathrm{~m} \mathrm{~s}^{-1}$ ) were produced directly above the soil surface; this can only occur above bare soils. In contrast, Maier et al. (2010) found an enhancement of soil gas transport at a forest site where wind speeds at soil surface were low, even during periods of high above-canopy wind speed. It is well known that a vertical gradient of wind speed from above the canopy to the soil exists due to the flow resistance of the trees. Moreover, at the canopy top, the mean wind speed profile shows an inflexion point where the wind shear is maximal and which is associated with the generation of turbulent kinetic energy (Novak et al., 2000b; Raupach et al., 1996). It is also known that increasing above-canopy wind speed correlates with increasing amplitudes and frequencies of air pressure fluctuations at soil surface (Mohr et al., 2016; Shaw et al., 1990; Sigmon, 1984; Sigmon et al., 1983). Yet, it is unclear whether the physical mechanism responsible for the PPE is caused by, (1), the local wind blowing over the soil surface or, (2), strong air pressure fluctuations that are generated during periods of high wind speed. 
Fig. 1. Experimental setup and simulation model used in this study, (a) Airflow, air pressure and (b) soil gas transport were measured simultaneously at the forest site in Hartheim. Afterwards, soil gas transport was simulated using (c) the geometry of the soil gas sampling system in its environment.

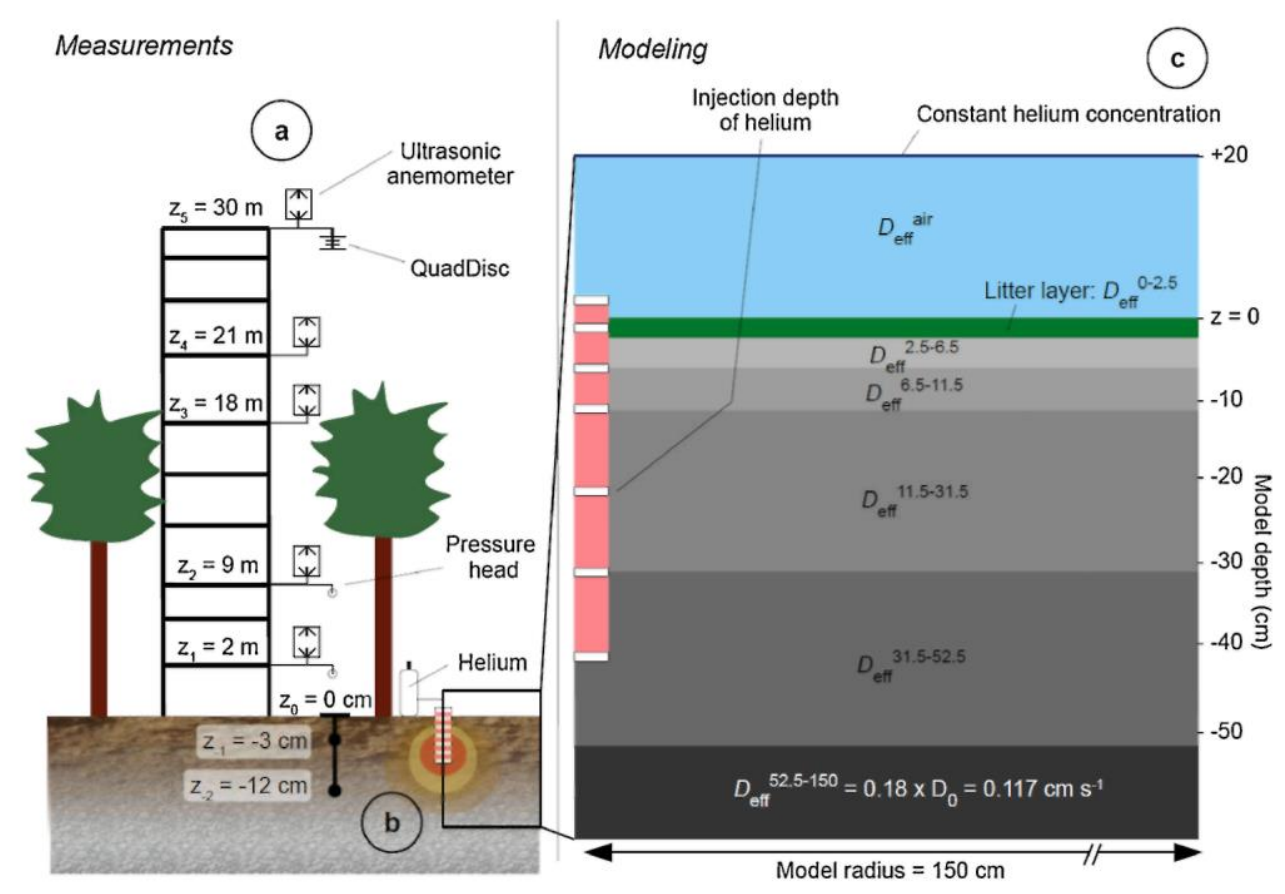

In the field, the PPE has been indirectly observed using $\mathrm{CO}_{2}$ concentration measurements in snowpacks (Bowling et al., 2009; Bowling and Massman, 2011) and in soils (Baldocchi and Meyers, 1991; Maier et al., 2010). However, using $\mathrm{CO}_{2}$ as a tracer gas in natural systems does not allow a clear separation between $\mathrm{CO}_{2}$ transport and $\mathrm{CO}_{2}$ production, both of which vary in time and space. The use of an inert tracer gas solves this issue (Kreamer et al., 1988). A novel method to monitor in situ soil gas transport by continuously injecting an inert tracer gas into the soil was developed by Laemmel et al. (2017a) which successfully monitored soil gas transport, including the effect of rain events (Laemmel et al., 2017a). In addition, this method allowed direct observation of the PPE on soil gas transport during two periods of high above-canopy wind speeds (Laemmel et al., 2017b).

The frequency of occurrence and the amplitude of the PPE as well as the physical mechanism responsible for the PPE at a forest site where usually low wind speeds near the ground are observed still needs investigation. In this study we combined measurements of airflow and air pressure above and below the canopy and in situ monitoring of soil gas transport to understand the coupling of gas transport processes between the atmosphere and the soil. 


\section{Material and methods}

\subsection{FIELD SITE}

The measurement campaign was conducted between June 10th 2016 and July 28th 2016. Measurements were carried out at the research site in Hartheim, Germany $\left(47^{\circ} 56^{\prime} \mathrm{N}, 7^{\circ} 36^{\prime} \mathrm{E}\right)$, within an even-aged Scots pine tree forest (Pinus sylvestris L.) planted in 1963 (Holst et al., 2008). The mean tree height (h) was $18 \mathrm{~m}$ and the mean stand density was 580 trees ha-1 $^{-1}$. The plant area index was 1.5. The soil is a Haplic Regosol (WRB classification, FAO, 2015) covered by a mean $0.02 \mathrm{~m}$ thick mull humus type composed of decomposed pine needles leaves. The litter layer had a high porosity (about $75 \%$ ) and a high air permeability (about $8000 \mu^{2}$ ). The mineral soil consists of a Ah horizon (0-0.2 $\mathrm{m}$ depth) with a loamy silt texture, covering a transitional Ah/C horizon with less silt and more gravel (0.2-0.4 $\mathrm{m}$ depth) and covering a $\mathrm{C}$ horizon composed of alluvial sand and gravel (Maier et al., 2010, 2017a). Total porosity was $0.63 \mathrm{~m}^{3} \mathrm{~m}^{-3}$ in $0-0.05 \mathrm{~m}$ depth, $0.58 \mathrm{~m}^{3} \mathrm{~m}^{-3}$ in $0.05-0.1$ $\mathrm{m}$ depth and around $0.52 \mathrm{~m}^{3} \mathrm{~m}^{-3}$ in $0.1-0.6 \mathrm{~m}$ depth (Laemmel et al., 2017a). The soil is well aerated throughout the entire profile (up to $1 \mathrm{~m}$ depth) and has a large volume of macropores (diameter > $300 \mu \mathrm{m}$ ) (Maier et al., 2012). Stone content is higher than $70 \%$ below $0.6 \mathrm{~m}$ depth. Forest growth at this site is limited by a low water availability and a low water holding capacity (high content of sand and gravel). Continuous measurements of barometric pressure, temperature profile $(2,9,18$, 21 and $30 \mathrm{~m}$ above ground and at 1, 3, 5, 10, 20 and $40 \mathrm{~cm}$ soil depths), volumetric soil water content (10 and $50 \mathrm{~cm}$ soil depths), and precipitation were made on site during the study period.

\subsection{MEASUREMENT OF AIRFLOW AND AIR PRESSURE FLUCTUATIONS}

\subsubsection{EXPERIMENTAL SETUP}

The 3D wind vector $(\boldsymbol{U})$ was measured (sampling frequency: $10 \mathrm{~Hz}$ ) below and above the forest canopy at $\left.z_{1}=2 \mathrm{~m}\left(z_{1} / h=0.11\right), z_{2}=9 \mathrm{~m}\left(z_{2} / h=0.50\right), z_{3}=18 \mathrm{~m} z_{3} / h=1.00\right), z_{4}=21 \mathrm{~m}\left(z_{4} / h=1.15\right)$ and $z_{5}=30 \mathrm{~m}\left(z_{5} / h=1.67\right)$ height with ultrasonic anemometers (81000VRE, R.M. Young Company, Traverse City, MI, USA). They were mounted on a $30 \mathrm{~m}$ tall lattice tower (Fig. 1a). Air pressure ( $p$ ) was measured (sampling frequency: $2 \mathrm{~Hz}$ ) at heights $z_{5}, z_{2}, z_{1}$, at the soil surface $\left(z_{0}=0 \mathrm{~m}\right)$, and in the soil $\left(z_{-1}=-0.03 \mathrm{~m}\right.$ and $z_{-2}=-0.12 \mathrm{~m}$ ) using differential pressure sensors (GMSD 2.5 MR, Greisinger Electronic $\mathrm{GmbH}$, Regenstauf, Germany). One inlet of each sensor was connected to an individual filtering box as described by Mohr et al. (2016). For the $p$ measurements at $z_{5}$ a QuadDisc pressure head was used (Nishiyama and Bedard, 1991) to reduce dynamic pressure effects caused by wind (Fig. 1a). Below the canopy spherically symmetric pressure heads were sufficient due to low wind speeds (Mohr et al., 2016). For $p$ measurements in the soil metal pipes (inner diameter: $2 \mathrm{~mm}$ ) were installed: one end of the pipe was open at the desired depth while the other end was connected to one inlet of the differential pressure sensor.

\subsubsection{DATA PROCESSING}

The $p$ signals were filtered to consider only the air pressure fluctuations with frequencies between $0.01 \mathrm{~Hz}$ and $0.1 \mathrm{~Hz}\left(p_{h}\right)$ since this frequency range is related to the PPE (Mohr et al., 2016). Mean wind speed $(|\overline{\boldsymbol{U}}|)$ and mean friction velocity $\left(u^{*}\right)$ at $z_{1}$ to $z_{5}$ were calculated for periods of $30 \mathrm{~min}$. As a proxy for the pressure-pumping intensity we used the pressure-pumping coefficient ( $P P C, \mathrm{~Pa} \mathrm{~s}^{-1}$ ) defined as $P P C=F_{S} \frac{1}{N} \sum_{n=1}^{N}|\Delta p|$, with $F_{S}$ being the sampling frequency of air pressure measurements (in $\mathrm{Hz}$ ), $N$ the number of measurements in a $30 \mathrm{~min}$ interval, and $\Delta p$ the air pressure difference (in Pa) between two subsequent $p$ measurements (Mohr et al., 2016). 


\subsection{IN SITU MONITORING OF SOIL GAS TRANSPORT}

\subsubsection{BACKGROUND}

Assuming molecular diffusion as main process of soil gas transport, the soil gas diffusion coefficient, $D_{S}$ (in $\mathrm{m}^{2} \mathrm{~s}^{-1}$ ), is commonly used to describe the passive gas transport capacity of soil. $D_{S}$ is known to vary with air-filled porosity over time. It decreases after rain events because water infiltrating into the soil reduces the air-filled porosity and showed the reverse effect during drying periods.

To quantify non-diffusive gas transport processes in soil an effective soil gas diffusion coefficient, $D_{\text {eff, }}$ can be defined (Maier et al., 2012). Under conditions where molecular diffusion is the main transport process of soil gases, $D_{\text {eff }} \approx D_{s}$. Under conditions with additional transport processes, $D_{\text {eff }}>$ $D_{S}$ or $D_{\text {eff }}=D_{S}+D_{x}\left(D_{x}>0\right)$, with $D_{x}$ being the part of $D_{\text {eff }}$ which is not explained by molecular diffusion. In the special case of soil gas transport enhanced by the PPE we define $D_{x}=D_{P P E}$ as the part of $D_{\text {eff }}$ that can be explained by the action of pressure-pumping on soil gas transport, i.e. $D_{\text {eff }}=D_{S}+D_{P P E}$ (Laemmel et al., 2017b).

The parameters $D_{s}, D_{\text {eff, }}$ and $D_{P P E}$ are dependent on temperature and barometric pressure, and are gas specific. To allow for the comparison of their temporal evolution without these influences, the parameters are normalized with $D_{0}$, the gas diffusion coefficient of the specific gas in the free air at the same temperature and barometric pressure i.e., $D_{S} / D_{0}, D_{\text {eff }} / D_{0}$ and $D_{P P E} / D_{0}$.

\subsubsection{EXPERIMENTAL SETUP}

Gas transport in the soil was monitored using the setup developed by Laemmel et al. (2017a). Helium (He), as a fast tracer gas $\left(D_{0}=0.65 \mathrm{~cm}^{2} \mathrm{~s}^{-1}\right.$ at air temperature $T_{0}=20^{\circ} \mathrm{C}$ and air pressure $\mathrm{P}_{0}=$ 1013.25 hPa, Fuller et al., 1966), was continuously injected into the soil. A soil gas injection and sampling device allows the sampling of free air at $1.5 \mathrm{~cm}$ above the humus layer (i.e. in the atmosphere) and soil air at the $-1.5 \mathrm{~cm},-6.5 \mathrm{~cm},-11.5 \mathrm{~cm},-31.5 \mathrm{~cm}$ and $-41.5 \mathrm{~cm}$ depths. Corresponding He concentrations $\left(C_{i}^{m}, i=+1.5,-1.5,-6.5,-11.5,-31.5\right.$ and $-41.5 \mathrm{~cm},{ }^{m}$ for measured) were measured automatically during a profile run lasting for $30 \mathrm{~min}$ by using a gas chromatograph (GC) system (3000 Micro GC Gas Analyzer, Inficon GmbH, Cologne, Germany, Molsieve column, thermal conductivity detector) connected to the sampling device via two multiport valves. Helium was injected with a peristaltic pump (Ismatec, Wertheim, Germany) at a depth of $-21.5 \mathrm{~cm}$ using He-filled bags placed in a tempered box to ensure a constant temperature, and therefore a constant injection rate. The injection rate was changed once (July 19th 2016) to adjust the $C_{i}^{m}$ range to the calibration range of the GC. The tempering of the box was done with a heating pad coupled to a thermostat. Therefore, to ensure a reliable tempering, the target temperature value was been set higher than the outside temperature (by default $30^{\circ} \mathrm{C}$ ) and needed to be adapted at very warm days. The nominal injection rate was $0.53 \mathrm{~mL} \mathrm{~min}^{-1}$ and $1.1 \mathrm{~mL} \mathrm{~min}{ }^{-1}$ after the change. Due to these low injection rates, advective transport of He induced in the soil was negligible (Laemmel et al., 2017a). The whole analysis system was placed in a second box. Air temperature in both boxes was monitored over time.

The conversion of the GC output data in ppm values was realized with a two-point calibration line (5 ppm and $2700 \mathrm{ppm} \mathrm{He}$ ). Regular calibration measurements were done to evaluate calibration shifts and to be able to correct them afterwards. $C_{i}^{m}$ values in ppm were converted to $C_{i}^{m}$ values in $\mathrm{mol} \mathrm{m} \mathrm{m}^{-3}$ using the barometric pressure and the temperature measured inside the $\mathrm{GC}$ box. 
The He injection rate into the soil was regularly checked by redirecting the He flow into a $300 \mathrm{ml}$ gas reservoir in which the increase of He concentration was measured. Considering that the variations of the barometric pressure and the air temperature in the He box directly influence the quantity of He injected, a daily mean injection rate of $\mathrm{He}$ in $\mathrm{mol} \mathrm{s}^{-1}$ was determined (variation within a daily period $<2 \%$ ).

\subsubsection{SIMULATION MODEL USING A FINITE ELEMENT MODELING SOFTWARE}

The He transport in the soil was modeled with the finite element modeling (FEM) software COMSOL 5.2 (COMSOL Multiphysics, Burlington, USA). The modeled system is a 2-D axisymmetric soil module form ( $1.5 \mathrm{~m}$ height $\times 3.0 \mathrm{~m}$ width) large enough to avoid any boundary effect. It includes an air layer (LO: 0 to $+20 \mathrm{~cm}$ ), six soil layers (the litter layer L1: 0 to $-2.5 \mathrm{~cm}, \mathrm{L2}:-2.5$ to $-6.5 \mathrm{~cm}$, L3: -6.5 to $-11.5 \mathrm{~cm}$, L4: -11.5 to $-31.5 \mathrm{~cm}$, L5: -31.5 to $-52.5 \mathrm{~cm}$ and L6: -52.5 to $-150 \mathrm{~cm}$ ), and the geometry of the gas sampling device (Fig. 1C). A He concentration of $5 \mathrm{ppm}$ was set as initial value for all the soil and air elements and also as boundary conditions at all sides of the model. Independent isotropic effective soil gas diffusion coefficients $\left(D_{\text {eff }}^{i}, i, i=\right.$ air, 0-2.5, 2.5-6.5, 6.5-11.5, 11.5-31.5, and 31.5-52.5) were assigned to the air layer L0 and the soil layers L1 to L5. For the soil layer L6, the gas transport was assumed to be purely diffusive ${ }^{\left(D_{e f f}^{52.5-150}=D_{S}^{52.5-150}\right)}$ and the temporal variability was determined considering soil moisture values measured at $-50 \mathrm{~cm}$ depth and using the $D_{s} / D_{0}$ models of Buckingham (1904) and Deepagoda et al. (2011), i.e.,

$$
\begin{aligned}
& \frac{D_{S}}{D_{0}}=\varepsilon^{2} \\
& \text { and } \\
& \frac{D_{S}}{D_{0}}=0.1\left[2\left(\frac{\varepsilon}{\varphi}\right)^{2}+0.04\left(\frac{\varepsilon}{\varphi}\right)\right] \\
& \text { with } \varepsilon \text { representing the air-filled porosity and } \varphi \text { the total soil por- } \\
& \text { osity. }
\end{aligned}
$$

The mean of the two values produced by these models was found to give a good estimation of $D_{e f f}^{52.5-150}$ for this measurement site (Laemmel et al., 2017a). Over the whole period a temporal average value of $D_{S} / D_{0}=0.18$ was calculated so that $D_{e f f}^{52.5-150}$ was set constant to $0.117 \mathrm{~cm}^{2} \mathrm{~s}^{-1}(0.18 \mathrm{x}$ $\left.D_{0}\right)$.

\subsubsection{SIMULATION OF THE HE CONCENTRATIONS}

To simulate the He concentrations, a parameter sweep process was used. Input data for the model of soil gas transport described above were, (1), a fixed sequence of $D_{\text {sff }}^{i}$ values for each layer (Table 1) and (2) a He injection rate. Output data of the simulation were the He concentrations at each sampling position for all possible $D_{\text {eff }}^{\underline{i}}$ combinations (= parameter sweep). The sequences of $D_{\text {eff }}^{D_{i}^{i}}$ values were the same for each day to simulate, while the He injection rate potentially varied each day. Thus a parameter sweep simulation per day would have been necessary. However, to reduce computing time and knowing that the influence of the He injection rate is linear on the $\mathrm{He}$

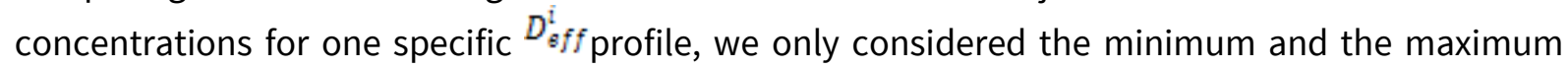
values of the He injection rate over the whole measurement campaign and carried out two forward simulations with these two values. Then the He concentrations for each day were computed using the both data sets and a linear interpolation for the actual daily injection. To further reduce computing time, the parameter sweep process with COMSOL was done with large spans between $D_{\text {eff }}^{i}$ values (Table 1 ). 
In a second step, we linearly interpolated the $D_{\text {fff }}^{\underline{i}}$ values and simulated corresponding He concentrations (software MATLAB, MathWorks, R2016b, Natick, USA) to improve the resolution between two consecutive $D_{\text {sff }}^{\underline{i}}$ values. Thus, a $D_{\text {sff }}^{i} / D_{0}$ resolution of 0.032 was reached for the two top soil layers and 0.016 for the third soil layer (Table 1 ).

Table 1 : Effective gas diffusion coefficients used in the two simulation steps.

\begin{tabular}{|c|c|c|c|c|c|}
\hline$\overline{D_{\text {sff }}^{1}}$ & Software & Minimum & Maximum & Span & Number of values \\
\hline \multirow[b]{2}{*}{$D_{\text {eff }}^{\text {air }}$} & COMSOL & $2.0 \mathrm{E}-4$ & $1.50 \mathrm{E}-3$ & $1.3 \mathrm{E}-4$ & 11 \\
\hline & MATLAB & $2.0 \mathrm{E}-4$ & $1.50 \mathrm{E}-3$ & $1.0 \mathrm{E}-4$ & 14 \\
\hline \multirow[b]{2}{*}{$D_{\text {eff }}^{0.25}$} & COMSOL & $3.0 \mathrm{E}-6$ & $6.30 \mathrm{E}-5$ & $2.0 \mathrm{E}-5$ & 4 \\
\hline & MATLAB & $3.0 \mathrm{E}-6$ & $6.30 \mathrm{E}-5$ & $2.0 \mathrm{E}-6$ & 31 \\
\hline \multirow[b]{2}{*}{$D_{\text {eff }}^{2.5-6.5}$} & COMSOL & $3.0 \mathrm{E}-6$ & $4.30 \mathrm{E}-5$ & $2.0 \mathrm{E}-5$ & 3 \\
\hline & MATLAB & $3.0 \mathrm{E}-6$ & 4.30E-5 & $2.0 \mathrm{E}-6$ & 21 \\
\hline \multirow[b]{2}{*}{$D_{\text {gff }}^{6.5-11.5}$} & COMSOL & $5.0 \mathrm{E}-7$ & $2.55 \mathrm{E}-5$ & $5.0 \mathrm{E}-6$ & 6 \\
\hline & MATLAB & $5.0 \mathrm{E}-7$ & $2.55 E-5$ & $1.0 \mathrm{E}-6$ & 26 \\
\hline & COMSOL & $5.0 \mathrm{E}-7$ & $2.05 E-5$ & $4.0 \mathrm{E}-6$ & 6 \\
\hline$D_{e f f}^{11.5-31}$ & MATLAB & $5.0 \mathrm{E}-7$ & $1.85 \mathrm{E}-5$ & $1.5 \mathrm{E}-6$ & 13 \\
\hline \multirow[b]{2}{*}{$D_{\text {eff }}^{31.5-52.5}$} & COMSOL & $5.0 \mathrm{E}-7$ & $2.05 E-5$ & $4.0 \mathrm{E}-6$ & 6 \\
\hline & MATLAB & $5.0 \mathrm{E}-7$ & $1.85 \mathrm{E}-5$ & $1.5 \mathrm{E}-6$ & 13 \\
\hline \multirow[t]{2}{*}{ Total } & COMSOL & / & / & I & 28512 \\
\hline & MATLAB & / & / & / & 40046916 \\
\hline
\end{tabular}

\subsubsection{FIT BETWEEN THE MEASURED AND THE SIMULATED HE CONCENTRATION DATA}

Each 30 min profile of measured He concentrations $\left(C_{i}^{m}\right)$ in a specific day was compared to all the profiles of simulated He concentrations $\left(C_{i}^{S},{ }^{S}\right.$ for simulated) for this day by computing the sum of the squared differences $(E)$ between $C_{i}^{S}$ and $C_{i}^{m}$ normalized by their mean value:

$$
E=\sum_{i=1}^{N=6}\left[\frac{\left(C_{i}^{s}-C_{i}^{m}\right)}{\left(\frac{C_{i}^{s}+C_{i}^{m}}{2}\right)}\right]^{2}
$$

The calculation of $E$ guaranteed that all concentration differences were equally considered, independently of their absolute values. The final $D_{\text {eff }} / D_{0}$ profile was chosen as the profile corresponding to the minimal value of $E$. 
Fig. 2. (a) Wind speed (|U |) above (blue) and below (orange) the canopy, (b) High-frequency part of air pressure $p\left(p_{h}\right.$, blue) and corresponding pressure-pumping coefficient (PPC, orange), for $p$ measured at soil surface, (c) Helium concentration $\left(C_{i}^{m}\right)$ measured at the five soil depths, (d) Modeled relative effective soil gas diffusion coefficients $D_{s f f}^{i} / D_{0}$. (e) Precipitation (blue) and volumetric soil moisture at $-10 \mathrm{~cm}$ depth (orange). The blue area on June 14, 2016 indicates the period shown in more details in Fig. 5 (For interpretation of the references to colour in this figure legend, the reader is referred to the web version of this article).
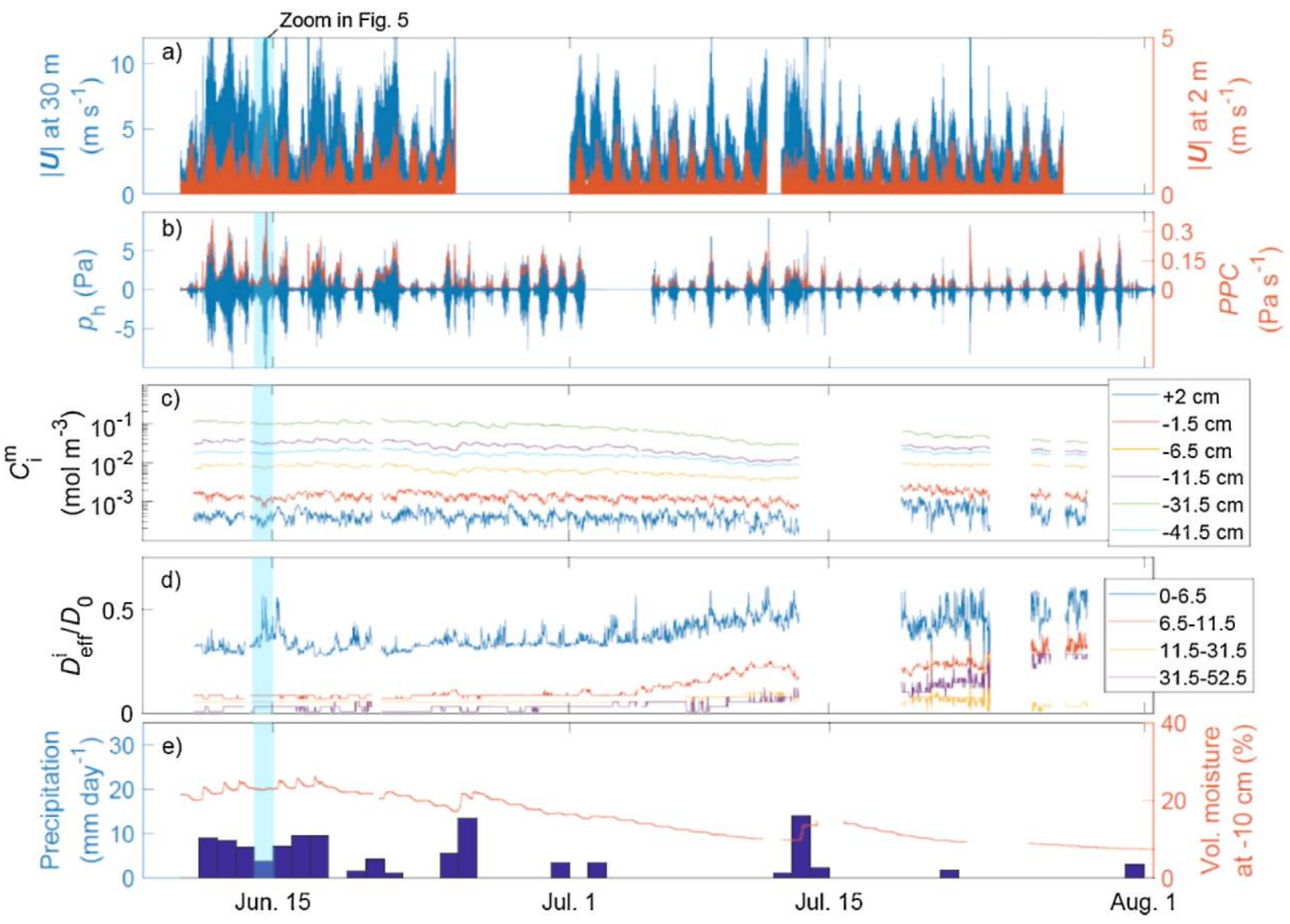
Fig. 3. Vertical profiles of (a) mean wind speed (| $\overline{\boldsymbol{U}} \mid)$ and (b) mean PPC values. The different curves correspond to the different classes established using the wind speed value at $18 \mathrm{~m}(\mathrm{a})$ and the PPC values at $9 \mathrm{~m}$ (b); the points correspond to the mean values observed at each height, (c) Correlation between the mean wind speeds at $2 \mathrm{~m}$ and at $30 \mathrm{~m}$. (d) Correlation between the mean PPC values at the soil surface and the mean wind speed at $30 \mathrm{~m}$. The four plots are based on mean values of all 30 minute periods of the measurement campaign.

a)

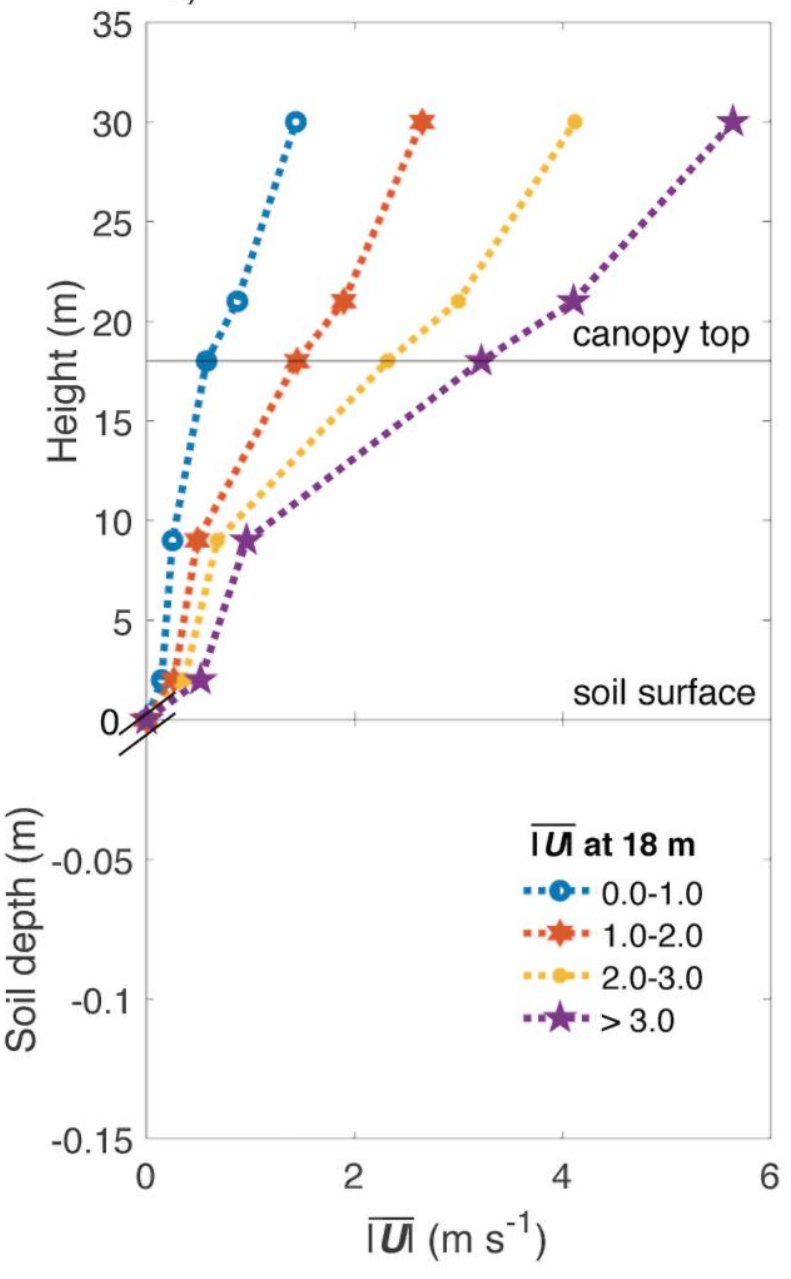

c)

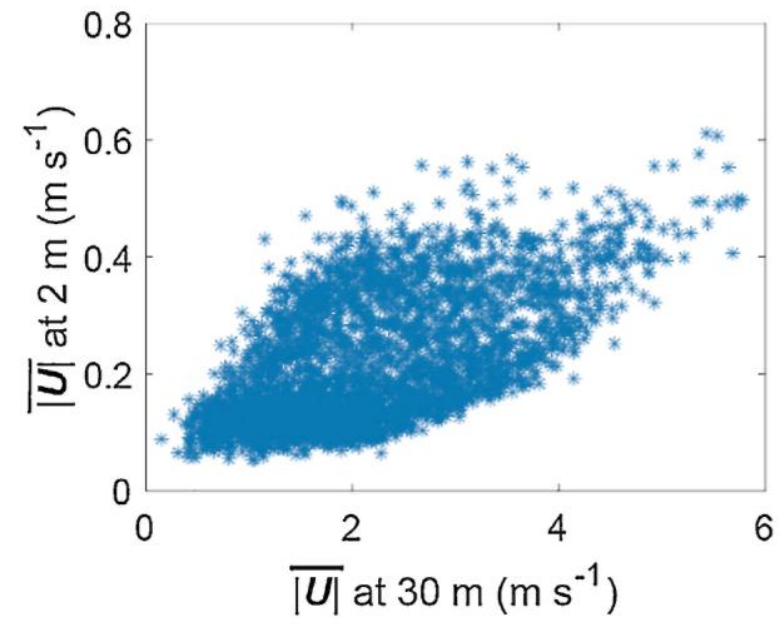

b)

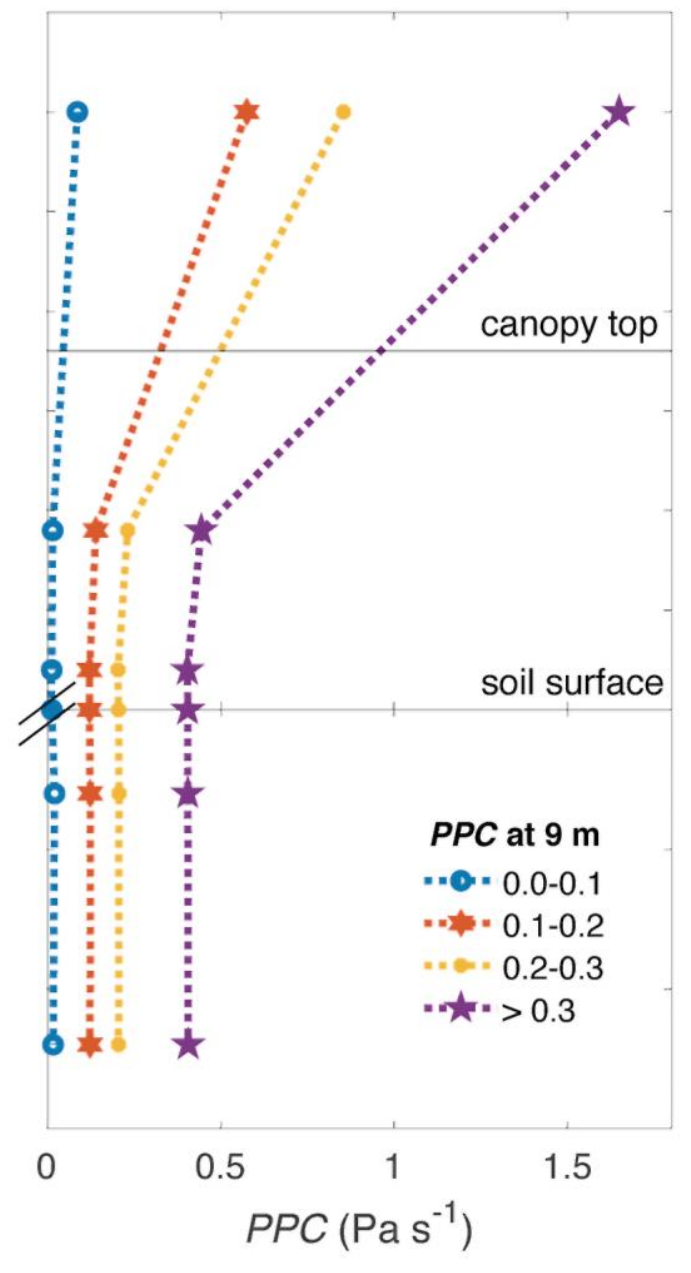

d)

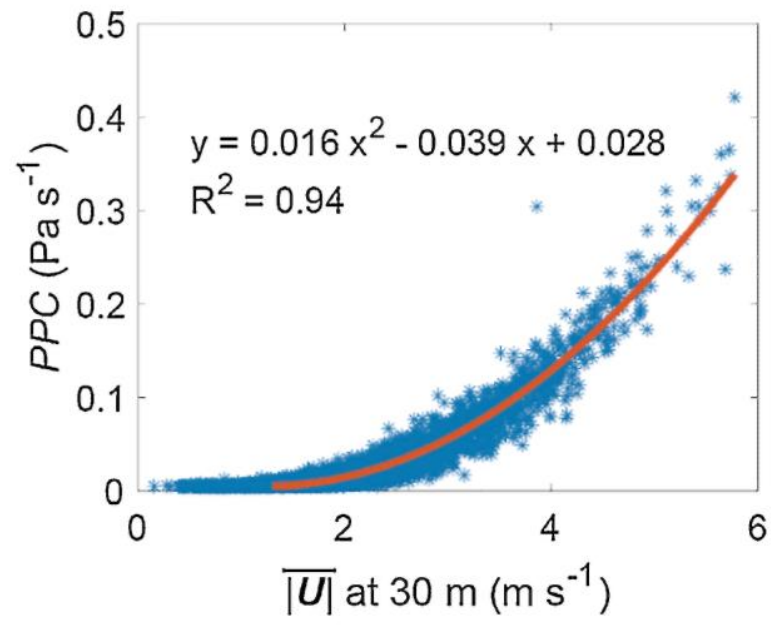




\subsubsection{EFFECT OF SOIL MOISTURE AND PRESSURE-PUMPING ON D $D_{\text {EFF }}$}

By monitoring the soil moisture at $-10 \mathrm{~cm}$ depth and knowing the total porosity $\phi$ at this depth $(\phi=$ 0.58, Laemmel et al., 2017a), the corresponding air-filled porosity during the whole measurement period can be estimated. Thus the $D_{\text {g.ff }}^{6.11 .5} / D_{0}$ values deduced from our method can be compared with the $D_{S} / D_{0}$ values obtained with the models of Buckingham (1904) and Deepagoda et al. (2011) (Eqs. 1 and 2).

$D_{\text {sff }}^{0-205}$ and $D_{\text {eff }}^{2.55-6.5}$ were averaged using the thickness of both layers as weight to produce $D_{\text {sff }}^{0-6.5}$ and thus to increase the reliability of the estimated effective diffusion coefficient of the upper part of the soil.

To detect pressure-pumping events, we considered all periods where the mean wind speed at $30 \mathrm{~m}$ height during four hours was higher than during the previous four hours by at least $0.5 \mathrm{~m} \mathrm{~s}^{-1}$ To evaluate the PPE on soil gas transport, for each pressure-pumping event, one calm period before and after this event were selected as time when molecular diffusion could be assumed as the only gas transport process, i.e. $D_{\text {eff }} / D_{0}=D_{S} / D_{0}$. A theoretical pure diffusive $D^{\text {th }} s / D_{0}$ value during the pressure-pumping event was calculated by linear temporal interpolation between the $D_{\text {eff }} / D_{0}$ $\left(=D_{S} / D_{0}\right)$ values of the calm peripheral periods. Then the part of the effective transport rate driven by pressure-pumping, $D_{P P E} / D_{0}$, was determined as difference between the modeled $D_{\text {efff }} / D_{0}$ and $D^{\text {th }} s / D_{0}$ (Laemmel et al., 2017b).

Fig. 4. Effective relative soil gas diffusion coefficient of the layer $L 3\left(D_{\text {eff }}^{6.5-11.5} / D_{0}\right)$ versus the air-filled porosity $(\varepsilon)$ and comparison with two common $D_{s} / D_{0}$ models (Buckingham, 1904 and Deepagoda et al., 2011).

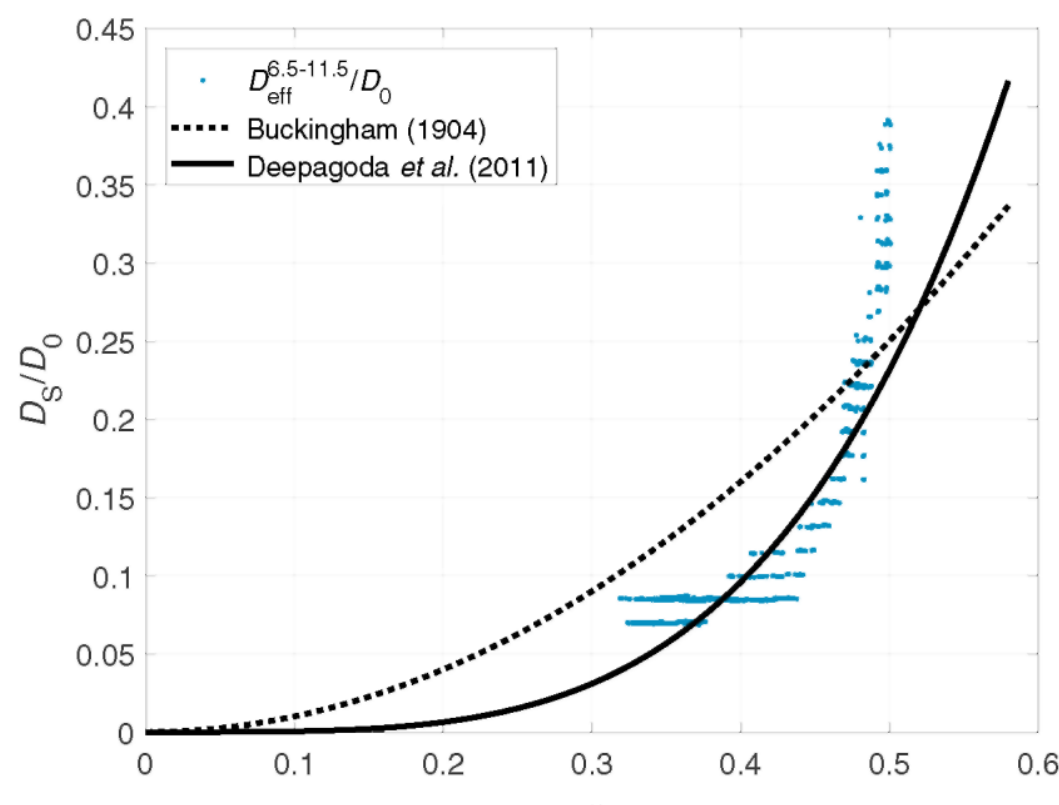


Fig. 5. (a) Wind speed (| $\boldsymbol{U} \mid$ ) above (blue) and below (orange) the canopy, (b) High-frequency part of air pressure $p\left(p_{h}\right.$, blue) and corresponding PPC values (orange), for $p$ measured at soil surface. (c) Modeled relative effective soil gas diffusion coefficient $D_{\text {aff }}^{0-6.5} / D_{0}$ (blue) and volumetric soil moisture at $-10 \mathrm{~cm}$ depth (orange). The areas $A^{1}{ }_{\text {ref, }} A$ and $A^{2}{ }_{\text {ref, }}$ in light blue are used to determine $D_{P P E}$ (see chapter 2.3.6) (For interpretation of the references to colour in this figure legend, the reader is referred to the web version of this article).
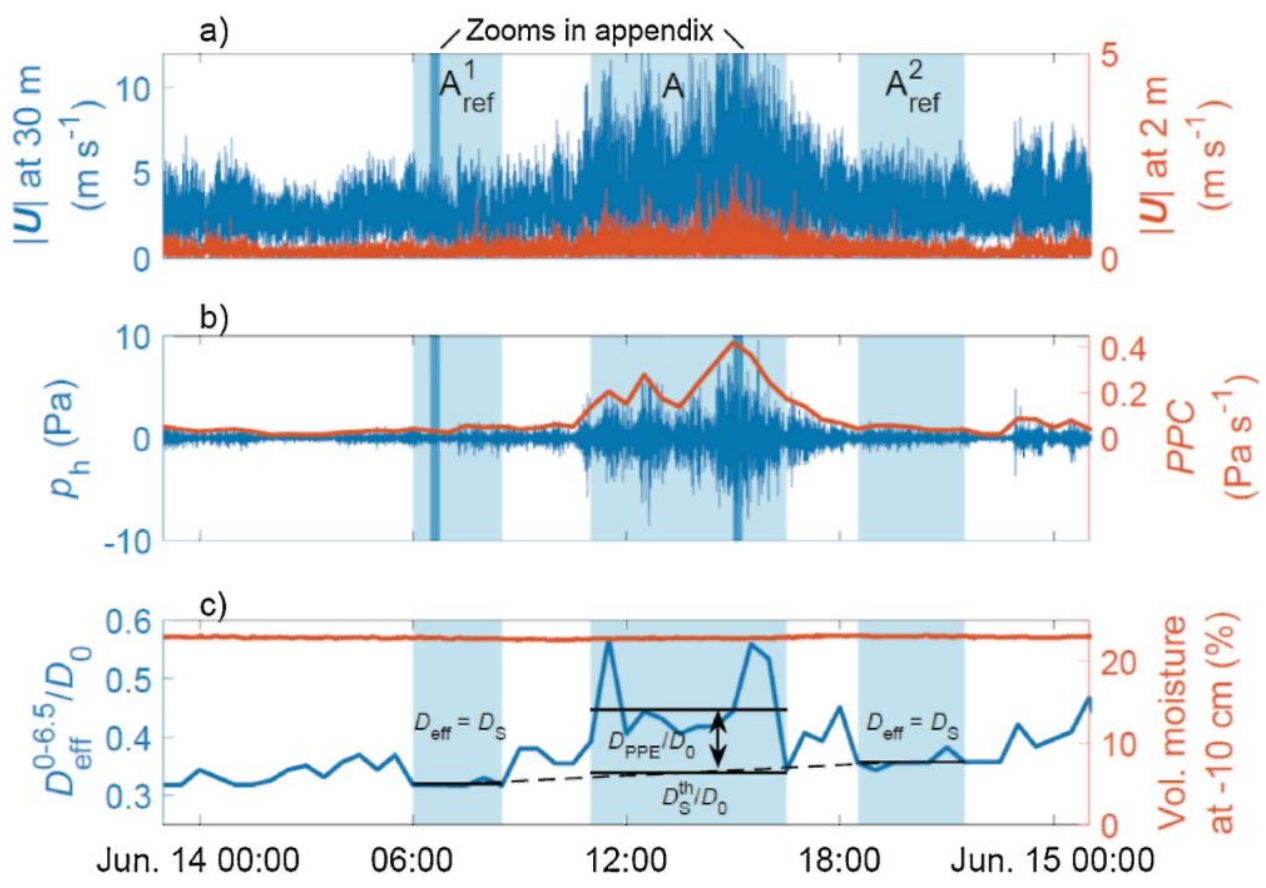

Fig. 6. Correlation between $D_{P P E}$ the part of $D_{\text {eff }}^{0-6.5}$ explained by pressure-pumping, normalized by the theoretical pure molecular diffusion coefficient $D^{\text {th }}{ }_{s}$ during the pressure-pumping event and corresponding (a) mean wind speed $|\overline{\mathbf{U}}|$ at $30 \mathrm{~m}$, (b) mean wind speed $|\overline{\mathbf{U}}|$ at $2 \mathrm{~m}$ and (c) mean PPC value at soil surface.
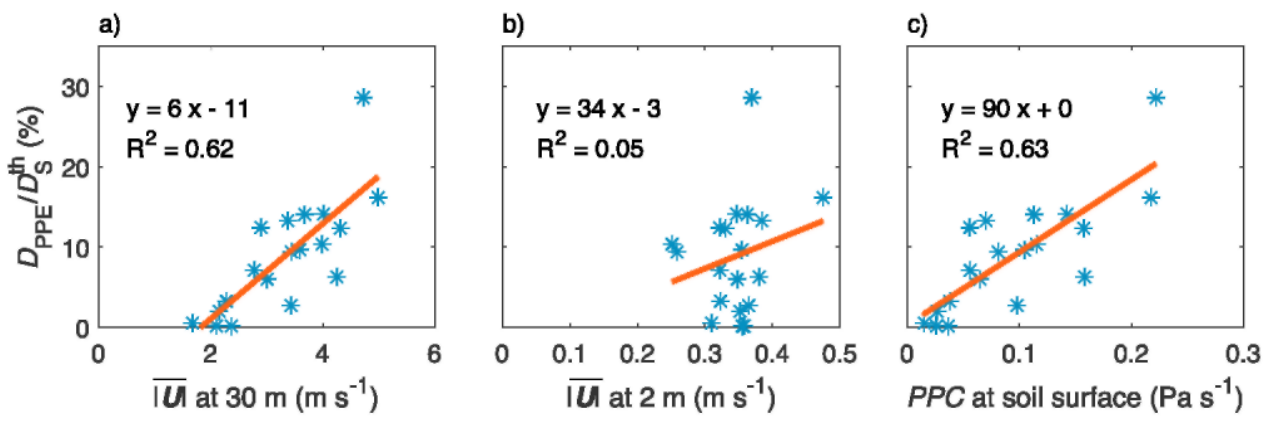
Fig. 7. Concept scheme of the enhancement of soil gas transport due to the pressure-pumping effect. During periods of high above-canopy wind speed, air pressure recorded below the canopy exhibits typical high frequency fluctuations (periods of 10-40s and amplitudes up to $10 \mathrm{~Pa}$ ) corresponding to coherent turbulent structures generated by flow instability processes at canopy top. While airflow at soil surface remains low, these fluctuations driven by above-canopy airflow penetrate into the soil and enhance the soil gas transport. The PPE enhances the soil gas transport between 0 and $-6.5 \mathrm{~cm}$ soil depth up to 30\%; no PPE could be measured deeper in the soil.

Low above-canopy wind speed

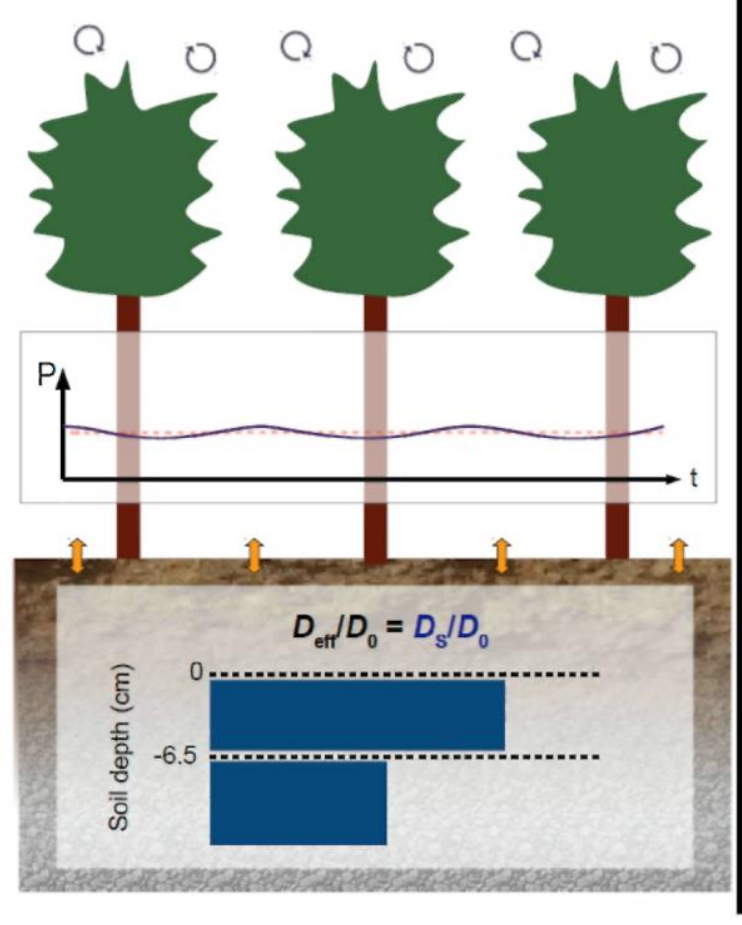

High above-canopy wind speed

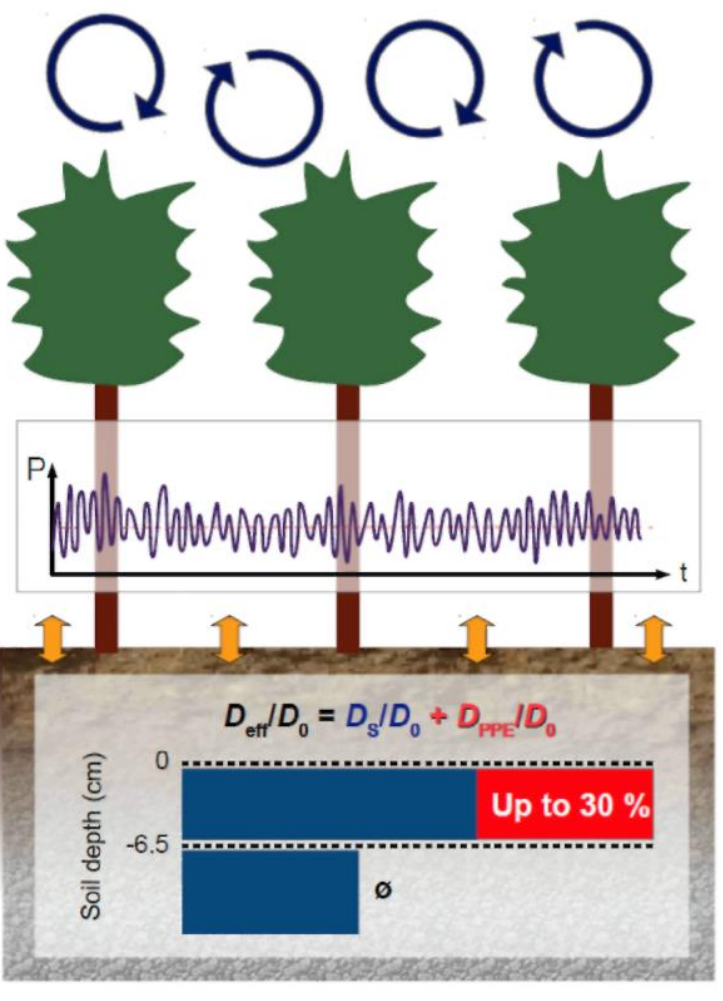

\section{Results and discussion}

\subsection{ANALYSIS OF AIRFLOW AND AIR PRESSURE FLUCTUATIONS}

Several periods with wind speed $>10 \mathrm{~ms}^{-1}$ at $30 \mathrm{~m}$ height were recorded in the measurement campaign (Fig. 2a). During these periods, the amplitudes of $p_{h}$ showed peaks up to $10 \mathrm{~Pa}$ and the $P P C$ reached values up to $0.3 \mathrm{~Pa} \mathrm{~s}^{-1}$ (Fig. $2 \mathrm{~b}$ ). Examples of $10 \mathrm{~Hz}$ measured wind speed $(|\boldsymbol{U}|)$ and $2 \mathrm{~Hz}$ filtered air pressure data $\left(p_{h}\right)$ from above and below the canopy during high and low wind speed situations are given in the Appendix.

Wind speed increased with height below and above the canopy starting with low wind speed at the soil surface (Fig. 3a and Appendix).

In contrast, the air pressure fluctuations below the canopy were similar at $9 \mathrm{~m}, 2 \mathrm{~m}$, at the soil surface $\left(z_{0}=0 \mathrm{~cm}\right)$ and within the soil (until $-12 \mathrm{~cm}$ ) and neither an amplitude loss nor a period shift was observed between these different locations. (Fig. 3b and Appendix).

Increasing above-canopy wind speed led to increasing below-canopy wind speed (Fig. 3a,c); 
however, the correlation is weak $\left(R^{2}=0.36\right)$. In contrast the relationship between above-canopy wind speed and $P P C$ values at $z_{0}$ is strong $\left(R^{2}=0.94, P P C=0.016\left|\overline{\boldsymbol{U}}_{5}\right|^{2}-0.039\left|\overline{\boldsymbol{U}}_{5}\right|+0.028\right)$, which is consistent with previous studies (Mohr et al., 2016; Shaw et al., 1990; Sigmon, 1984; Sigmon et al., 1983). Thus, it seems that above-canopy airflow conditions constitute a better proxy for the PPC values at soil surface than the local wind above the ground. Based on the similar air pressure signals measured below the canopy and in the soil (Fig. 3b and appendix), we postulate that the air pressure fluctuations are caused by above-canopy airflow characteristics and not by airflow characteristics at soil surface (Mohr et al., 2016, 2017; Shaw and Zhang, 1992). Simulations of the interaction between above-canopy airflow and forest canopy showed that coherent structures are generated at canopy height due to flow instability processes (Finnigan et al., 2009; Finnigan and Brunet, 1995; Novak et al., 2000a; Raupach et al., 1996). Therefore, we think that the air pressure fluctuations are flow effects and that measuring them below the canopy could provide a possibility to further investigate these above-canopy coherent structures.

The $P P C$ values at $30 \mathrm{~m}$ were significantly higher than those below the canopy. However, these data have to be interpreted with caution, since the design of the QuadDisc pressure head was only validated for barometric air pressure measurements, i.e. for air pressure fluctuations in the $\mathrm{hPa}$ range (Lanzinger and Schubotz, 2012) but not for air pressure fluctuations of $1 \mathrm{~Pa}$ amplitude or less. In particular, the dynamic pressure effect due to high wind speeds occurring above the forest canopy should be further investigated.

\subsection{ANALYSIS OF SOIL GAS TRANSPORT}

Measured He concentrations $C_{i}^{m}$ were highest close to the injection depth $(-21.5 \mathrm{~cm})$ and decreased towards the soil surface and deeper soil (Fig. 2C) which is consistent with validation experiments under laboratory conditions (Laemmel et al., 2017a). ${ }^{D_{\text {eff }}^{i}} / D_{0}$ generally decreased with depth but also varied substantially with time (Fig. 2 d). Some of the variations of $D_{\text {sff }}^{i} / D_{0}$ and $C_{i}^{m}$ can be explained by variations in precipitation and soil moisture (Fig. 2e). Rain events temporarily reduced He exchange between soil and atmosphere and created a temporary increase of $C_{i}^{m}$ at all depths and a decrease of $D_{\text {eff }}^{i} / D_{0}$ (e.g. on June 16th, June 17 th and June 25 th). The measurement campaign included four weeks with little rain when volumetric soil moisture at $-10 \mathrm{~cm}$ soil depth decreased from $22 \%$ to $10 \%$. This loss of water in the porous structure was consistent with a constant decrease of $C_{i}^{m}$ and an increase of $D_{\text {sff }}^{\underline{i}} / D_{0}$ values.

The in situ determined ${ }^{D_{\text {sff }}^{6.5-11.5}} / D_{0}$ values were compared to common diffusivity models (Eqs. 1 and 2) derived from laboratory measurements on soil cores (Fig. 4). These in situ values were slightly lower than the values obtained with the Buckingham model for $\varepsilon<0.5$ (offset of up to 0.05 ) and in the same range of the values of the Dee-pagoda model especially in the range $0.4<\varepsilon<0.5$. For $\varepsilon$ values outside this range, the curves diverged, illustrating the difficulty to find a priori the correct theoretical model for a specific soil and depth. 


\subsection{PRESSURE-PUMPING EFFECT ON SOIL GAS TRANSPORT}

Increases in $D_{\text {sff }}^{0-6.5} / D_{0}$ were observed for periods when peak values of $|\boldsymbol{U}|$ at $30 \mathrm{~m}$ were $>5 \mathrm{~m} \mathrm{~s}^{-1}$ and peak values of $P P C$ were $>0.2$ Pa s (Fig. 2a,b). We attributed these enhancements of

$D_{\text {sff }}^{0-6.5} / D_{0}$ values during periods of high wind speed to the PPE. We detected 19 periods with temporary $D_{\text {eff }}^{0-6.5} / D_{0}$ increases (an example is shown in Fig. 5).

Resulting $D_{P P E} / D_{S}^{\text {th }}$ values showed a strong correlation with the mean above-canopy wind speed $\left(\mathrm{R}^{2}\right.$ $=0.62$, Fig. 6a). Considering atmospheric parameters measured close to soil surface, the correlation between $D_{P P E} / D_{S}^{\text {th }}$ and $|\overline{\boldsymbol{U}}|$ at $2 \mathrm{~m}$ was weak $\left(\mathrm{R}^{2}=0.05\right.$, Fig. $\left.6 \mathrm{~b}\right)$ while the correlation between $D_{P P E} / D_{S}^{\text {th }}$ and the $P P C$ values at soil surface was strong $\left(\mathrm{R}^{2}=0.63\right.$, Fig. $\left.6 \mathrm{c}\right)$. The similar correlations for $P P C$ and $|\overline{\mathbf{U}}|$ at $30 \mathrm{~m}$ with $D_{P P E} / D_{S}^{\text {th }}$ are consistent with the good correlation between these two variables (Fig. 3d). The linear fit for $|\overline{\mathbf{U}}|$ at $30 \mathrm{~m}$ exhibited a wind speed threshold value of about $1.6 \mathrm{~m} \mathrm{~s}^{-1}$ for pressure-pumping events. No effect of pressure-pumping on soil gas transport could be detected during periods where $|\overline{\boldsymbol{U}}|$ values at $30 \mathrm{~m}$ were non-zero and less than the threshold value. Neither was there a relation between $D_{P P E} / D_{S}^{\text {th }}$ and the friction velocity calculated at $z_{1}\left(\mathrm{R}^{2}=0.00\right)$. Furthermore, $D_{\text {eff }} / D_{0}$ in the deeper soil layers did not increase during periods of high wind speed.

Previous studies dealing with the PPE commonly associated this effect with high wind speed conditions but without clear ideas about the mechanisms driving the enhancement of the gas transport rate in the soil. In addition to the PPE, wind could also directly flush high permeable layers above soils (Hirsch et al., 2004). Effectively, constant wind over a porous media can induce gas movement, mainly horizontally, in the porous structure itself, in particular in snow (Drake et al., 2017; Massman and Frank, 2006). However, mean wind speed measured at $2 \mathrm{~m}$ during the temporary increases of $D_{\text {eff }}^{0-6.5}$ was lower than $0.4 \mathrm{~m} \mathrm{~s}^{-1}$, i.e. much lower than wind speeds commonly recorded in open landscape. Furthermore, the airflow at $2 \mathrm{~m}$ was also highly variable in amplitude and direction so that a relative stable pressure gradient due to wind flowing over the soil surface could not establish over a longer time. Considering these characteristics and the good correlation between $D_{P P E} / D_{S}^{\text {th }}$ and the PPC values at soil surface, we postulate that the mechanism responsible for pressure-pumping in soil at the study site is related to the air pressure fluctuations at soil surface rather than the airflow above the soil (Fig. 7).

As microscopic mechanism explaining the PPE of soil gas transport, Maier et al. (2012) proposed gas dispersion caused by the air pressure fluctuations inducing vertical oscillating movements of the soil air column. These movements locally create high horizontal concentration gradients between main vertical pores and lateral dead-end pores. This modifies the pure diffusive vertical gas concentration gradient and enhances the vertical gas transport into the soil. In this study, a maximum enhancement of $30 \%$ was measured. It is difficult to compare our results to studies focusing on the effect of oscillating airflow on soil gas transport. Several setups have been already tested but the characteristics of the air pressure fluctuations artificially produced strongly differed from the air pressure fluctuations observed in situ (amplitudes up to $10 \mathrm{~Pa}$ and periods between 10 $\mathrm{s}$ and $40 \mathrm{~s}$, see in Appendix and Mohr et al., 2016). The substrates used were also generally artificial and so not equivalent to the natural structure of soils, e.g. they were characterized by high air permeability values. For example, Scotter et al. (1967) and Scotter and Raats (1968) produced air pressure sinusoidal oscillations with periods between $0.04 \mathrm{~s}$ and $4 \mathrm{~s}$ and amplitudes $>100 \mathrm{~Pa}$. The substrates were spheres or aggregates with diameters ranging 0.5 to $4.0 \mathrm{~mm}$. They observed enhancements of the $D_{\text {eff }} / D_{s}$ values up to $80 \%$. Poulsen and Sharma (2011) applied air pressure fluctuations with amplitudes between $100 \mathrm{~Pa}$ and $385 \mathrm{~Pa}$ and periods between $8 \mathrm{~s}$ and $33 \mathrm{~s}$ on two sandy substrates; they showed enhancements of the $D_{\text {eff }} / D_{s}$ values up to $240 \%$. We recommend repeating such laboratory measurements but with air pressure fluctuations with naturally 
occurring characteristics and real soil samples.

Studying the effect of non-diffusive gas transport processes in soil and particularly the PPE is of special interest because they directly influence soil aeration. Soil aeration controls the supply of oxygen in the soil and allows aerobic or anaerobic conditions, on which other soil processes like denitrification and methane production are coupled. Moreover, the oxidation of $\mathrm{CH}_{4}$ in upland forests is assumed to be controlled by the supply rate of $\mathrm{CH}_{4}$ and $\mathrm{O}_{2}$ from the atmosphere to methanotrophic bacteria located in the topsoil (Maier et al., 2017b; Smith et al., 2000). Increasing gas transport by PPE could potentially increase the $\mathrm{CH}_{4}$ consumption. Furthermore, research focusing on the influence of PPE on the widely-used chamber method needs to be conducted.

\section{Conclusions}

Our results demonstrate that pressure-pumping driven by wind-induced air pressure fluctuations can significantly enhance soil gas transport during periods of high above-canopy wind speed. Wind speed near the soil surface is negligible in forests and the enhancement of effective gas diffusion coefficient clearly correlates with the strength of the below-canopy air pressure fluctuations and less with the mean wind speed above soil surface. Thus we postulate that at this forest site, the pressure-pumping effect is caused by air pressure fluctuations rather than by local airflow above soil surface. These air pressure fluctuations seem to be related to above-canopy airflow.

Further studies are needed to clarify the physical processes behind the translation of abovecanopy airflow to soil surface air pressure fluctuations and to the PPE occurring in the porous soil structure. The quantification of the PPE on soil gas flux needs also the definition of a proxy describing the soil susceptibility to pressure-pumping.

\section{ACKNOWLEDGEMENTS}

This work has been supported by the German Research Foundation (SCHA 1528/1-1 and SCHI 868/3-1). We would like to thank the anonymous reviewer and M. Novak for their substantial contributions and constructive comments. 


\section{Appendix A}

\section{See Fig A1 and A2.}

Fig. A1. High-frequency measurements $(10 \mathrm{~Hz})$ of absolute wind speed $|\boldsymbol{U}|$ at $(a, f) z_{5}=30 \mathrm{~m},(\mathrm{~b}, \mathrm{~g}) \mathrm{z}_{4}=$ $21 \mathrm{~m},(c, h) z_{3}=18 \mathrm{~m},(d, i) z_{2}=9 \mathrm{~m}$ and $(e, j) z_{1}=2 \mathrm{~m}$ during one period with low mean wind speed (June 14th 2016, 06:30-06:45 AM) and one period with high mean wind speed (June 14th 2016, 03:0003:15 PM). A decrease of the wind speed amplitude is clearly visible along the profile.
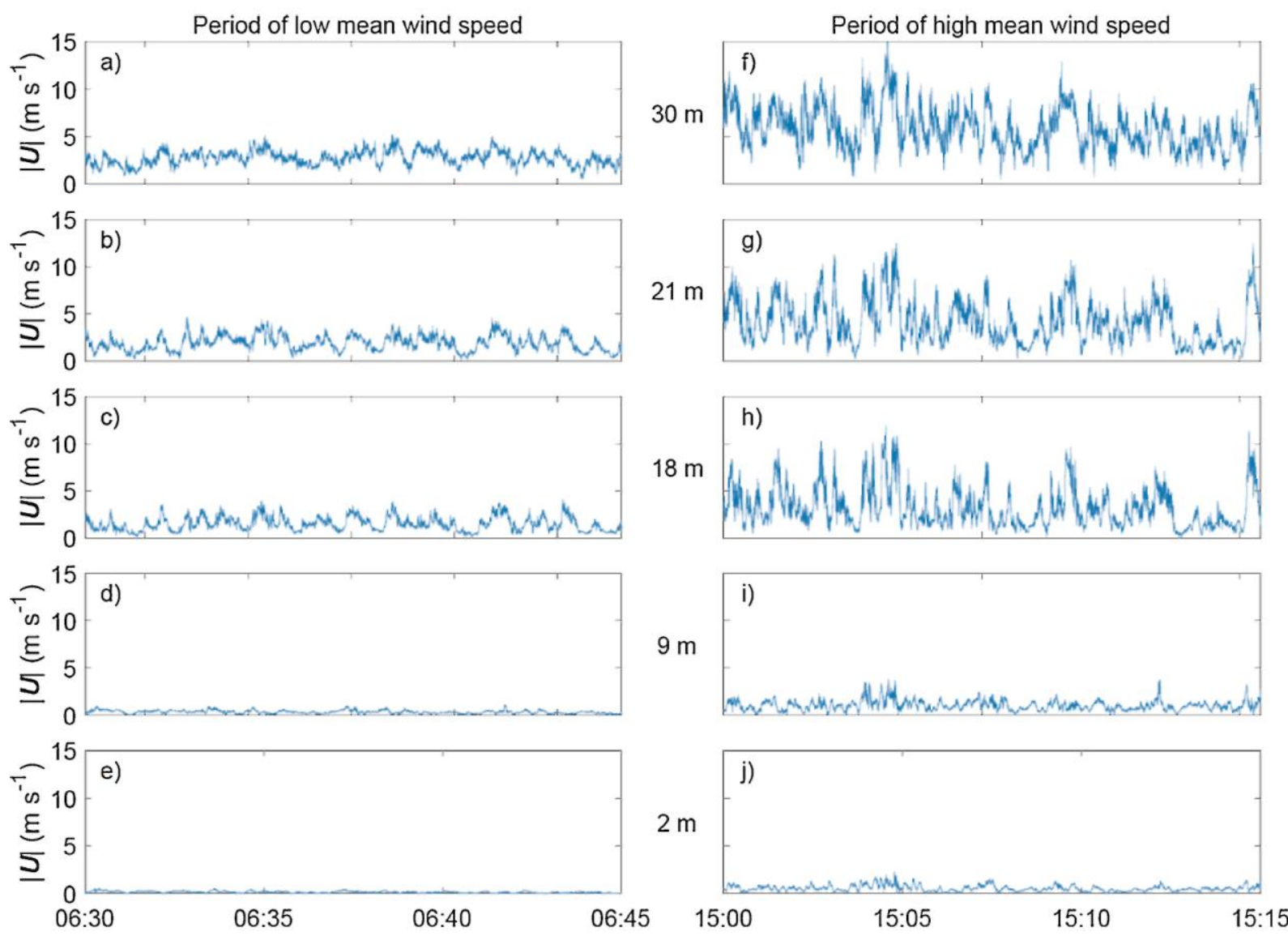
Fig. A2. High-frequency $(2 \mathrm{~Hz})$ filtered air pressure data $p_{h}$ at $(a, f) z_{5}=30 \mathrm{~m},(b, g) z_{2}=9 \mathrm{~m},(c, h) z_{1}=2$ $m,(d, i) z_{0}=0 \mathrm{~m}$ and $(e, j) z_{-2}=-12 \mathrm{~cm}$ during one period with low mean wind speed (June 14th 2016, 06:30-06:45 AM) and one period with high mean wind speed (June 14th 2016, 03:00-03:15 PM). It is clearly visible that the air pressure fluctuations during the period of high mean wind speed are measured coherently from $9 \mathrm{~m}$ to $-12 \mathrm{~cm}$ (without significant loss of amplitude and without time lags).
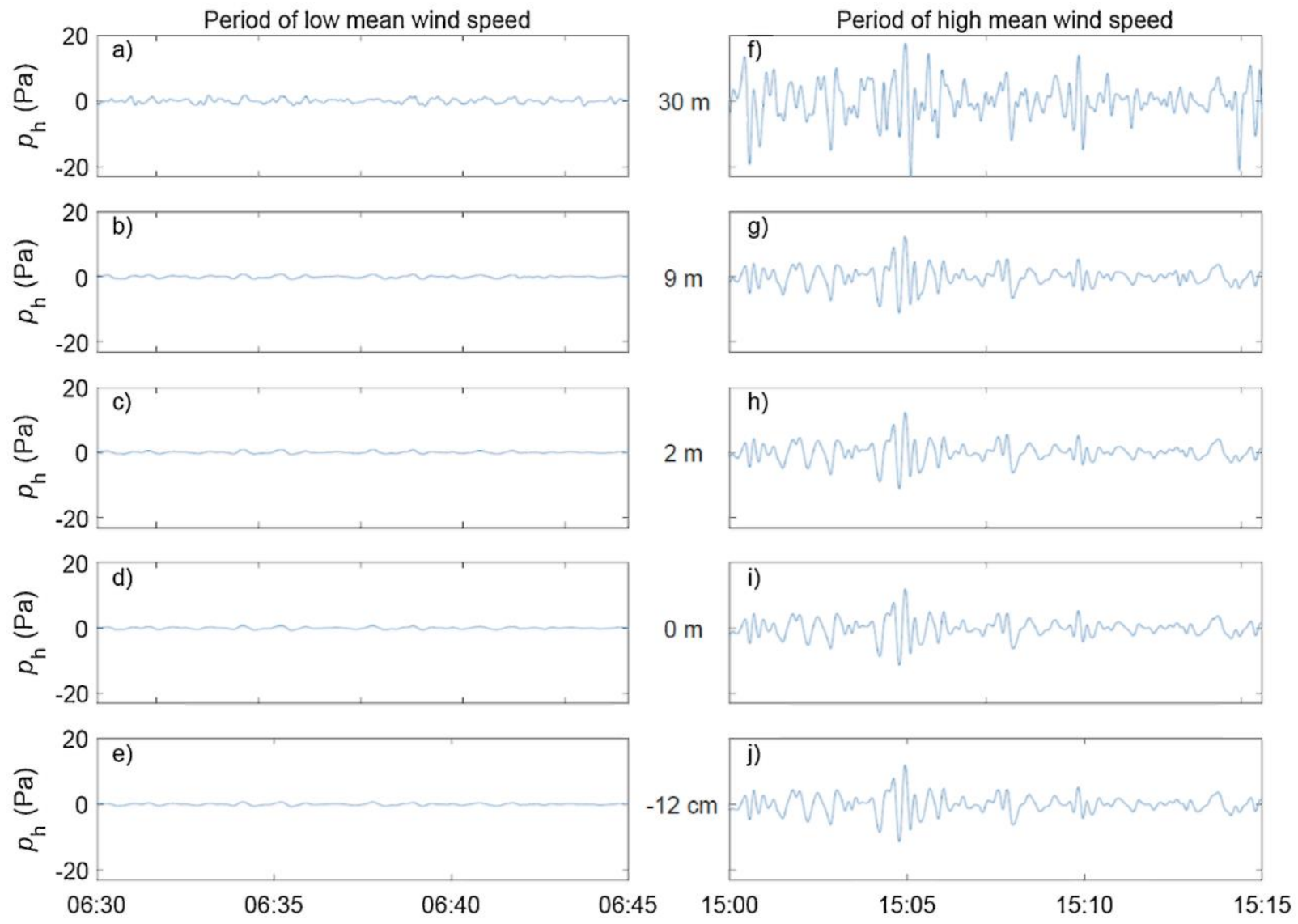

\section{REFERENCES}

Amos, R.T., Blowes, D.W., Smith, L., Sego, D.C., 2009. Measurement of wind-induced pressure gradients in a waste rock pile. Vadose Zone J. 8, 953-962. https://doi.org/ 10.2136/vzj2009.0002.

Auer, L.H., Rosenberg, N.D., Birdsell, K.H., Whitney, E.M., 1996. The effects of barometric pumping on contaminant transport. J. Contam. Hydrol. 24, 145-166. https://doi. org/10.1016/S01697722(96)00010-1.

Baldocchi, D.D., Meyers, T.P., 1991. Trace gas exchange above the floor of a deciduous forest: 1. Evaporation and $\mathrm{CO}_{2}$ efflux. J. Geophys. Res. 96, 7271-7285. https://doi. org/10.1029/91JD00269.

Bowling, D.R., Massman, W.J., 2011. Persistent wind-induced enhancement of diffusive $\mathrm{CO}_{2}$ transport in a mountain forest snowpack. J. Geophys. Res. 116, G04006.

https://doi.org/10.1029/2011JG001722.

Bowling, D.R., Massman, W.J., Schaeffer, S.M., Burns, S.P., Monson, R.K., Williams, M.W., 2009. Biological and physical influences on the carbon isotope content of $\mathrm{CO}_{2}$ in a subalpine forest snowpack, Niwot Ridge, Colorado. Biogeochemistry 95, 37-59. https://doi.org/10.1007/s10533-0089233-4. 
Buckingham, E., 1904. Contributions to Our Knowledge of the Aeration of Soils. U.S.Dept. of Agriculture, Bureau of Soils, Washington, D.C. Clements, W.E., Wilkening, M.H., 1974. Atmospheric pressure effects on ${ }^{222} \mathrm{Rn}$ transport across the Earth-air interface. J. Geophys. Res. 79, 5025-5029. https://doi.org/10.1029/JC079i033p05025.

Colbeck, S.C., 1989. Air movement in snow due to windpumping. J. Glaciol. 35, 209-213. https://doi.org/10.3189/S0022143000004524.

Deepagoda, T.K.K.C., Moldrup, P., Schjønning, P., Jonge, L.W., de, Kawamoto, K., Komatsu, T., 2011. Density-corrected mo dels for gas diffusivity and air permeability in unsaturated soil. Vadose Zone J. 10, 226-238. https://doi.org/10.2136/vzj2009. 0137.

Drake, S.A., Selker, J.S., Higgins, C.W., 2017. Wind enhances differential air advection in surface snow at sub-meter scales. Cryosphere 11, 2075-2087. https://doi.org/10.5194/tc-11-2075-2017.

FAO, 2015. Word Reference Base for Soil Resources 2014, Update 2015, World Soil. FAO, Rome.

Finnigan, J.J., Brunet, Y., 1995. Turbulent airflow in forests on flat and hilly terrain. In: Coutts, M.P., Grace, J. (Eds.), Wind and Trees. Cambridge University Press, Cambridge, pp. 3-40.

https://doi.org/10.1017/CB09780511600425.002.

Finnigan, J.J., Shaw, R.H., Patton, E.G., 2009. Turbulence structure above a vegetation canopy. J. Fluid Mech. 637, 387-424. https://doi.org/10.1017/ S0022112009990589.

Fuller, E.N., Schettler, P.D., Giddings, J.C., 1966. A new method for prediction of binary gas-phase diffusion coefficients. Ind. Eng. Chem. 58, 18-27. https://doi.org/10. 1021/ie50677a007.

Hirsch, A.I., Trumbore, S.E., Goulden, M.L., 2004. The surface $\mathrm{CO}_{2}$ gradient and pore-space storage flux in a high-porosity litter layer. Tellus B 56, 312-321. https://doi. org/10.1111/j.16000889.2004.00113.x.

Hoist, J., Barnard, R., Brandes, E., Buchmann, N., Gessler, A., Jaeger, L., 2008. Impacts of summer water limitation on the carbon balance of a Scots pine forest in the southern upper Rhine plain. Agric. For. Meteorol. 148, 1815-1826. https://doi.0rg/10.1016/j. agrformet. 2008.06.008.

Kreamer, D.K., Weeks, E.P., Thompson, G.M., 1988. A field technique to measure the tortuosity and sorption-affected porosity for gaseous diffusion of materials in the unsaturated zone with experimental results from near Barnwell, South Carolina. Water Resour. Res. 24, 331-341. https://doi.org/10.1029/WR024i003p00331.

Laemmel, T., Maier, M., Schack-Kirchner, H, Lang, F., 2017a. An in situ method for realtime measurement of gas transport in soil. Eur. J. Soil Sci. 68, 156-166. https://doi.

org/10.1111/ejss.12412.

Laemmel, T., Mohr, M., Schack-Kirchner, H, Schindler, D., Maier, M., 2017b. Direct observation of wind-induced pressure-pumping on gas transport in soil. Soil Sci. Soc. Am. J. 81, 770-774. https://doi.org/10.2136/sssaj2017.01.0034n.

Lanzinger, E., Schubotz, K., 2012. A Laboratory Intercomparison of Static Pressure Heads. Brussels. Maier, M., Longdoz, B., Laemmel, T., Schack-Kirchner, H, Lang, F., 2017a. 2D profiles of $\mathrm{CO}_{2}, \mathrm{CH}_{4}$, $\mathrm{N}_{2} \mathrm{O}$ and gas diffusivity in a well aerated soil: measurement and Finite Element Modeling. Agric. For. Meteorol. 247, 21-33. https://doi.org/10.10167/j. agrformet. 2017.07.008.

Maier, M., Paulus, S., Nicolai, C, Stutz, K., Nauer, P., 2017b. Drivers of plot-scale variability of CH4 consumption in a well-aerated pine forest soil. Forests 8, 193. https://doi.org/10.3390/f8060193.

Maier, M., Schack-Kirchner, H, Aubinet, M., Goffin, S., Longdoz, B., Parent, F., 2012. Turbulence effect on gas transport in three contrasting forest soils. Soil Sci. Soc. Am. J. 76, 1518-1528. https://doi.org/10.2136/sssaj2011.0376. 
Maier, M., Schack-Kirchner, H, Hildebrand, E.E., Hoist, J., 2010. Pore-space $\mathrm{CO}_{2}$ dynamics in a deep, well-aerated soil. Eur. J. Soil Sci. 61, 877-887. https://doi.org/10.1111/J.1365-2389.2010.01287.X.

Massman, W.J., Frank, J.M., 2006. Advective transport of $\mathrm{CO}_{2}$ in permeable media induced by atmospheric pressure fluctuations: 2 . Observational evidence under snow-packs. J. Geophys. Res. 111, G03005. https://doi.org/10.1029/2006JG000164.

Massman, W.J., Sommerfeld, R.A., Mosier, A.R., Zeller, K.F., Hehn, T.J., Rochelle, S.G., 1997. A model investigation of turbulence-driven pressure-pumping effects on the rate of diffusion of $\mathrm{CO}_{2}, \mathrm{~N}_{2} \mathrm{O}$, and $\mathrm{CH}_{4}$ through layered snowpacks. J. Geophys. Res. Atmos. 102, 18851-18863.

https://doi.org/10.1029/97JD00844.

Massmann, J., Farrier, D.F., 1992. Effects of atmospheric pressures on gas transport in the vadose zone. Water Resour. Res. 28, 777-791. https://doi.org/10.1029/91WR02766.

Mohr, M., Laemmel, T., Maier, M., Schindler, D., 2017. Spatial variability of wind-induced air pressure fluctuations responsible for pressure pumping. Tellus B Chem. Phys. Meteorol. 69, 1361757. https://doi.org/10.1080/16000889.2017.1361757.

Mohr, M., Laemmel, T., Maier, M., Schindler, D., 2016. Analysis of air pressure fluctuations and topsoil gas concentrations within a Scots pine forest. Atmosphere (Basel) 7, 125.

https://doi.org/10.3390/atmos7100125.

Nawaz, M.F., Bourrie, G., Trolard, F., 2013. Soil compaction impact and modelling, a review. Agron. Sustain. Dev. 33, 291-309. https://doi.org/10.1007/s13593-011-0071-8.

Nishiyama, R.T., Bedard, A.J., 1991. A "Quad-Disc" static pressure probe for measurement in adverse atmospheres: with a comparative review of static pressure probe designs. Rev. Sci. Instrum. 62, 2193-2204. https://doi.org/10.1063/1.1142337.

Novak, M.D., Chen, W., Orchansky, A.L., Ketler, R., 2000a. Turbulent exchange processes within and above a straw mulch. Agric. For. Meteorol. 102, 139-154. https://doi. org/10.1016/S01681923(00)00095-2.

Novak, M.D., Warland, J.S., Orchansky, A.L., Ketler, R., Green, S., 2000b. Wind tunnel and field measurements of turbulent flow in forests. Part I: uniformly thinned stands. Boundary-Layer Meteorol. 95, 457-495. https://doi.org/10.1023/ A:1002693625637.

Poulsen, T.G., Furman, A., Liberzon, D., 2017a. Effects of wind speed and wind gustiness on subsurface gas transport. Vadose Zone J. 16. https://doi.org/10.2136/vzj2017.04. 0079.

Poulsen, T.G., Pourber, A., Furman, A., Papadikis, K., 2017b. Relating wind-induced gas exchange to near-surface wind speed characteristics in porous media. Vadose Zone J. 16. https://doi.org/10.2136/vzj2017.02.0039.

Poulsen, T.G., Sharma, P., 2011. Apparent porous media gas dispersion in response to rapid pressure fluctuations. Soil Sci. 176, 635-641. https://doi.org/10.1097/SS. 0b013e3182372fae.

Pourbakhtiar, A., Poulsen, T.G., Wilkinson, S., Bridge, J.W., 2017. Effect of wind turbulence on gas transport in porous media: experimental method and preliminary results. Eur. J. Soil Sci. 68, 48-56. https://doi.org/10.1111/ejss.12403.

Raupach, M.R., Finnigan, J.J., Brunei, Y., 1996. Coherent eddies and turbulence in vegetation canopies: the mixing-layer analogy. Boundary-Layer Meteorol. 78, 351-382. https://d0i.0rg/l $0.1007 / B F 00120941$.

Scanlon, B.R., Nicot, J.P., Massmann, J.W., 2001. Soil gas movement in unsaturated systems. In: Warrick, A.W. (Ed.), Soil Physics Companion. CRC Press, pp. 100. 
Scotter, D.R., Raats, P.A.C., 1968. Dispersion in porous mediums due to oscillating flow. Water Resour. Res. 4, 1201-1206. https://doi.org/10.1029/WR004i006p01201.

Scotter, D.R., Thurtell, G.W., Raats, P.A.C., 1967. Dispersion resulting from sinusoidal gas flow in porous materials. Soil Sci. 104, 306-308. https://doi.org/10.1097/ 00010694-196710000-00012.

Shaw, R.H., U Paw, K.T., Zhang, X.J., Gao, W., Den Hartog, G., Neumann, H.H., 1990. Retrieval of turbulent pressure fluctuations at the ground surface beneath a forest. Boundary-Layer Meteorol. 50, 319-338. https://doi.org/10.1007/BF00120528.

Shaw, R.H., Zhang, X.J., 1992. Evidence of pressure-forced turbulent flow in a forest. BoundaryLayer Meteorol. 58, 273-288. https://doi.org/10.1007/BF02033828.

Sigmon, J., 1984. Leaf emergence and flow-through effects on mean windspeed profiles and microscale pressure fluctuations in a deciduous forest. Agric. For. Meteorol. 31, 329-337. https://doi.org/10.1016/0168-1923(84)90045-5.

Sigmon, J.T., Knoerr, K.R., Shaughnessy, E.J., 1983. Microscale pressure fluctuations in a mature deciduous forest. Boundary-Layer Meteorol. 27, 345-358. https://doi.org/10. 1007/BF02033744.

Smith, K.A., Ball, T., Conen, F., Dobbie, K.E., Massheder, J., Rey, A., 2003. Exchange of greenhouse gases between soil and atmosphere: interactions of soil physical factors and biological processes. Eur. J. Soil Sci. 54, 779-791. https://doi.org/10.1046/j. 1351-0754.2003.0567.X.

Smith, K.A., Dobbie, K.E., Ball, B.C., Bakken, L.R., Sitaula, B.K., Hansen, S., Brumme, R., Borken, W., Christensen, S., Prieme, A., Fowler, D., Macdonald, J.A., Skiba, U., Klemedtsson, L., KasimirKlemedtsson, A., Degorska, A., Orlanski, P., 2000. Oxidation of atmospheric methane in Northern European soils, comparison with other ecosystems, and uncertainties in the global terrestrial sink. Glob. Chang. Biol. 6, 791-803. https://doi.org/10.1046/j.1365-2486.2000.00356.x. 